INTERVENTIONAL CARDIOLOGY AND SURGERY

\title{
Clinical and haemodynamic profiles of young, middle aged, and elderly patients with mitral stenosis undergoing mitral balloon valvotomy
}

\author{
T R D Shaw, N Sutaria, B Prendergast
}

Heart 2003;89:1430-1436

See end of article for authors' affiliations

Correspondence to: DrT RD Shaw, Department of Cardiology, Western General Hospital, Crewe Road, Edinburgh, UK; trd.shaw@virgin.net

Accepted 29 May 2003

\begin{abstract}
Objective: To compare the clinical characteristics, haemodynamic findings, and symptomatic outcome in four age groups of patients in the UK undergoing percutaneous mitral balloon valvotomy.

Design: A review of patients with mitral stenosis treated by balloon dilatation.

Setting: Western General Hospital, Edinburgh, a cardiac referral centre.

Results: Of 405 patients who had mitral balloon valvotomy, 19 were aged under 40 years, 101 aged 4054, 173 aged 55-69, and 112 were 70 years old or more. Medical co-morbidity and Parsonnet score for risk at surgery increased notably with age. Older patients had greater symptomatic limitation and a more severe degree of mitral stenosis, with more valve degenerative change. The incidence of atrial fibrillation, mitral reflux, left ventricular impairment, coronary artery disease, and aortic valve disease increased progressively with age. Before balloon dilatation the right ventricular systolic and left atrial pressures were similar in all age groups, but younger patients had a higher transmitral gradient and cardiac output. After balloon dilatation the younger patients achieved a greater increase in valve area. Complications of balloon valvotomy were more common in the older patients. At five years after balloon dilatation the percentages of patients in each age group who were in New York Heart Association classes I and II were $87 \%, 63 \%, 36 \%$, and $19 \%$, respectively. Mortality at five years was $0 \%, 5 \%, 31 \%$, and $59 \%$.

Conclusions: Percutaneous balloon valvotomy gives a good haemodynamic and symptomatic result in patients under 55. In older patients improvement is often less pronounced and less sustained, but the procedure is a well tolerated palliative treatment for those unsuitable for surgery.
\end{abstract}

A cute rheumatic fever showed a remarkable decrease in incidence in the UK and western Europe during the 20th century. In Denmark, where rheumatic fever has been a notifiable disease, the incidence fell from 200 per 100000 in 1900 to 11 per 100000 in $1962 .{ }^{12}$ The death rate from rheumatic fever in England and Wales reduced by two thirds between 1901 and 1937, ${ }^{3}$ although in 1938 the London County Council had a register of over 22800 children $(2.6 \%$ of the child population) who had had rheumatic fever. ${ }^{4}$ Rheumatic heart disease was then the most common cause of death in people aged under $40^{5}$ and accounted for almost $40 \%$ of all patients admitted to hospital with cardiac disease. ${ }^{6}$

The second world war gave a unique opportunity to assess the prevalence of rheumatic heart disease in Britain at that time. Of 6.6 million men aged 18-41 who were examined for military service, one million were rejected on health grounds. ${ }^{5}$ Heart disease was present in 9\% and was considered to be rheumatic in $80 \%$ on the basis of clinical signs and chest $x$ ray. ${ }^{7}$ It was estimated that rheumatic heart disease affected 300000 British men and women between 18-41 years of age. ${ }^{5}$ In the USA there was a similar frequency of cardiovascular disease in potential recruits to their armed forces. ${ }^{8}$ The incidence of rheumatic fever fell in England and Wales by a further 72\% between 1948 and 1961, ${ }^{3}$ and acute rheumatic fever is now rarely seen in Britain. The USA had a similar reduction in incidence." In developing countries, however, where more than $80 \%$ of children live, rheumatic fever has increased notably ${ }^{2}$ and there is now more rheumatic heart disease in the world as a whole than ever before.

The often long delay between the initial acute rheumatic episode and the subsequent development of severe chronic valve disease means that patients with rheumatic valve disease still present to British cardiac departments, sometimes more than half a century after the initiating event. New cases are supplemented by those who had a previous successful valvotomy but develop restenosis.

We review the clinical and haemodynamic features and the immediate and longer term symptomatic outcome found in young, middle aged, and elderly patients in the UK who underwent percutaneous mitral balloon valvotomy during the period 1986 to 2000 .

\section{PATIENTS AND METHODS}

Between 1986 and 2000, 405 patients had a completed percutaneous mitral balloon valvotomy at the Western General Hospital, Edinburgh. Of these, 19 were aged under 40, 101 were aged 40-54 years, 173 were aged 55-69, and 112 were aged 70 or over. The characteristics of the patients in these age groups are given in table 1.

Patients had been referred from hospitals throughout all of Scotland and 20 had been referred from England. In the young $(<40$ years) age group, five of the 19 patients $(26 \%)$ had been born outside the UK. The youngest UK born patient was 29. In the lower and upper middle aged groups five of the 274 patients $(2 \%)$ were born abroad. All of the elderly patients were UK born.

Mitral balloon valvotomy was undertaken if mitral stenosis was judged to cause or contribute to continuing symptoms despite medical treatment and if associated mitral reflux was not more than mild. It was the preferred treatment for patients with a mitral valve suitable for a commissurotomy and offered as palliative treatment for those judged as unsuitable for cardiac surgery. A Parsonnet score ${ }^{10}$ was calculated for each patient. 


\begin{tabular}{|c|c|c|c|c|c|}
\hline & \multicolumn{4}{|c|}{ Age group (years) } & \multirow[b]{2}{*}{ p Value } \\
\hline & $<40$ & $40-54$ & $55-69$ & $\geqslant 70$ & \\
\hline Number of patients & $19(5 \%)$ & $101(25 \%)$ & $173(43 \%)$ & $112(28 \%)$ & \\
\hline Age (years), mean & $34.2(6.0)$ & $47.7(4.3)$ & $61.6(4.3)$ & $75.5(4.4)$ & \\
\hline Female & $15(79 \%)$ & $77(76 \%)$ & 134 (77\%) & $95(85 \%)$ & 0.32 \\
\hline Past history of RF & $4(21 \%)$ & 38 (38\%) & $72(42 \%)$ & $44(39 \%)$ & 0.32 \\
\hline Past history of Vty & $1(5 \%)$ & $23(23 \%)$ & $44(25 \%)$ & 20 (18\%) & 0.14 \\
\hline Sinus rhythm & $15(79 \%)$ & $41(41 \%)$ & 39 (23\%) & $17(15 \%)$ & $<0.001$ \\
\hline Mitral reflux & $5(26 \%)$ & $28(28 \%)$ & $61(35 \%)$ & $49(44 \%)$ & 0.09 \\
\hline LV impairment & $1(5 \%)$ & $4(4 \%)$ & $23(13 \%)$ & $15(13 \%)$ & 0.06 \\
\hline Coronary disease & $0(0 \%)$ & $5(5 \%)$ & $39(23 \%)$ & $43(38 \%)$ & $<0.01$ \\
\hline Aortic valve disease & $2(11 \%)$ & $17(17 \%)$ & $24(24 \%)$ & $26(23 \%)$ & 0.19 \\
\hline NYHA symptom score & $2.5(0.7)$ & $2.7(0.7)$ & $2.9(0.7)$ & $3.3(0.6)$ & $<0.001$ \\
\hline Frusemide dose ( $\mathrm{mg} /$ day) & 34 (37) & $53(38)$ & $72(71)$ & $97(66)$ & $<0.001$ \\
\hline Fluoroscopic calcification & $0.1(0.2)$ & $0.4(0.9)$ & $0.8(1.1)$ & $1.2(1.2)$ & $<0.001$ \\
\hline Echo score & $4.4(1.8)$ & $5.5(2.4)$ & $6.7(2.8)$ & $7.9(3.1)$ & $<0.001$ \\
\hline $\begin{array}{l}\text { Commissure calcification } \\
\text { grade }\end{array}$ & $0.16(0.37)$ & $0.30(0.67)$ & $0.48(0.81)$ & $0.49(0.76)$ & 0.21 \\
\hline $\begin{array}{l}\text { LA thrombus in patients } \\
\text { having TOE }\end{array}$ & $0 / 13(0 \%)$ & $6 / 76(8 \%)$ & $14 / 127(11 \%)$ & $15 / 88(18 \%)$ & $<0.05$ \\
\hline Unsuitability for MVR & $0(0 \%)$ & $5(5 \%)$ & $36(21 \%)$ & $67(60 \%)$ & $<0.001$ \\
\hline Parsonnet score & $10.2(5.6)$ & $10.0(5.1)$ & $12.5(5.3)$ & $24.6(8.6)$ & $<0.001$ \\
\hline
\end{tabular}

Suitability for surgical treatment was as judged by a cardiac surgeon or referring cardiologist. The reasons for unsuitability for operation were as follows: additional severe inoperable non-mitral cardiac disease in eight, severe pulmonary disease in 33 , and frailty and medical problems in 67. The most common medical problems were renal failure, chronic neurological disability, coexisting cancer, severe arthritis, morbid obesity, diabetic complications, and moderate cardiac or pulmonary disease. Frequently several medical problems co-existed.

In an additional 11 patients, mitral balloon valvotomy had been attempted but not completed. The causes of failure to complete balloon dilatation were failed transseptal puncture (2), intensive vasovagal reaction at transseptal puncture (1), balloon unable to cross the mitral orifice (5), haemopericardium (2), and stroke from dislodged atrial thrombus (1). The success rate for completed valvotomy using the Inoue balloon was $99 \%$, and with cylindrical balloons-used before the Inoue equipment was available in the UK ${ }^{11}$ - it was $91 \%$.

\section{Echocardiographic assessment}

All patients had a full transthoracic echocardiographic study before the procedure. The echo score for mitral valve degenerative change was calculated as described by Wilkins and colleagues. ${ }^{12}$ Commissure calcification was graded as 0 4, with each half commissure showing bright confluent echoes extending across the commissure being scored as $1 .{ }^{13}$ Mitral valve calcification was assessed visually at fluoroscopy and graded as absent, mild, moderate, or severe (scored as 0 3). All patients undergoing mitral balloon valvotomy had some commissural fusion.

The latter 301 patients also underwent a transoesophageal study immediately before balloon valvotomy in order to identify left atrial thrombus. Left atrial thrombus was not considered to be a contraindication to balloon valvotomy if the thrombus was not at the atrial septum, was laminar with a smooth surface, or was within the left atrial appendage.

\section{Percutaneous mitral balloon valvotomy}

The initial 70 cases were treated using single or double cylindrical balloons. In 335 subsequent patients the Inoue equipment and method were used. ${ }^{14}$ We found these two methods gave the same haemodynamic result. ${ }^{11}$

Right and left heart pressures were recorded using $10 \mathrm{~cm}$ above the table as zero. Mean valve gradient was measured by planimetry. Mitral reflux was assessed by left ventricular angiography and graded as absent, mild, moderate, or severe. Cardiac output was estimated from oxygen saturations using assumed oxygen uptake ${ }^{15}$; to avoid left to right shunting from the atrial crossing point samples were taken from the vena cava. Mitral valve area was calculated by the Gorlin equation. Coronary angiography was carried out in all patients who had any chest discomfort or were aged over 40. Sedation was not given unless the patient was anxious. Four patients required a general anaesthetic, three for severe anxiety and one because of severe arthritis. In four patients, access to the right femoral vein was not possible and the left femoral vein was used. One patient was pregnant at the time of the procedure. In one patient a tricuspid balloon dilatation was carried out during the same procedure, and five patients had a coronary angioplasty immediately after the mitral balloon dilatation. All procedures were carried out by one operator (TRDS). Haemodynamic measurement of valve area was used for the assessment of mitral stenosis, as elderly patients are often difficult echo subjects and valve calcification makes orifice planimetry less reliable. A good immediate outcome was taken to be a valve area after final balloon dilatation of more than $1.50 \mathrm{~cm}^{2}$ without the development of severe mitral reflux.

\section{Follow up}

The patients' clinical status during three to four months of follow up (New York Heart Association (NYHA) symptom class, need for mitral valve replacement, or death) was recorded at a clinic visit, and for long term follow up, by telephone contact with the patient, relatives, general practitioner, referring cardiologist, or health board mortality records. Long term follow up was $97 \%$ complete.

\section{Statistical analysis}

Results are expressed as mean (SD) unless stated otherwise. Differences between age groups were determined by analysis 
of variance. A probability value of $p<0.05$ was taken to be significant. For immediate outcome, multivariate analysis was done using a binary end point (final valve area $>1.5 \mathrm{~cm}^{2}$ without severe mitral reflux). For long term outcome, multivariate analysis was done according to the binary end point of whether the patient was alive without undergoing valve replacement or repeat balloon valvotomy, using the Cox regression model. A commercially available statistical package (SPSS for Windows) was used for all calculations.

\section{RESULTS}

\section{Clinical characteristics}

The mean (SD) age of these 405 patients was 60.7 (12.8) years (range 13-89 years). This is 24 years older than the mean age of the first 140 Western General Hospital patients to have a closed surgical mitral valvotomy in the early 1950s (mean age 36.8 (0.77) years, range 16-59 years) (fig 1).

Several clinical characteristics showed a progressive change with age (table 1). Retention of sinus rhythm became much less common, with only $15 \%$ of those aged over 70 remaining in normal rhythm compared with $79 \%$ of those aged under 40. Coronary artery disease increased significantly with age-
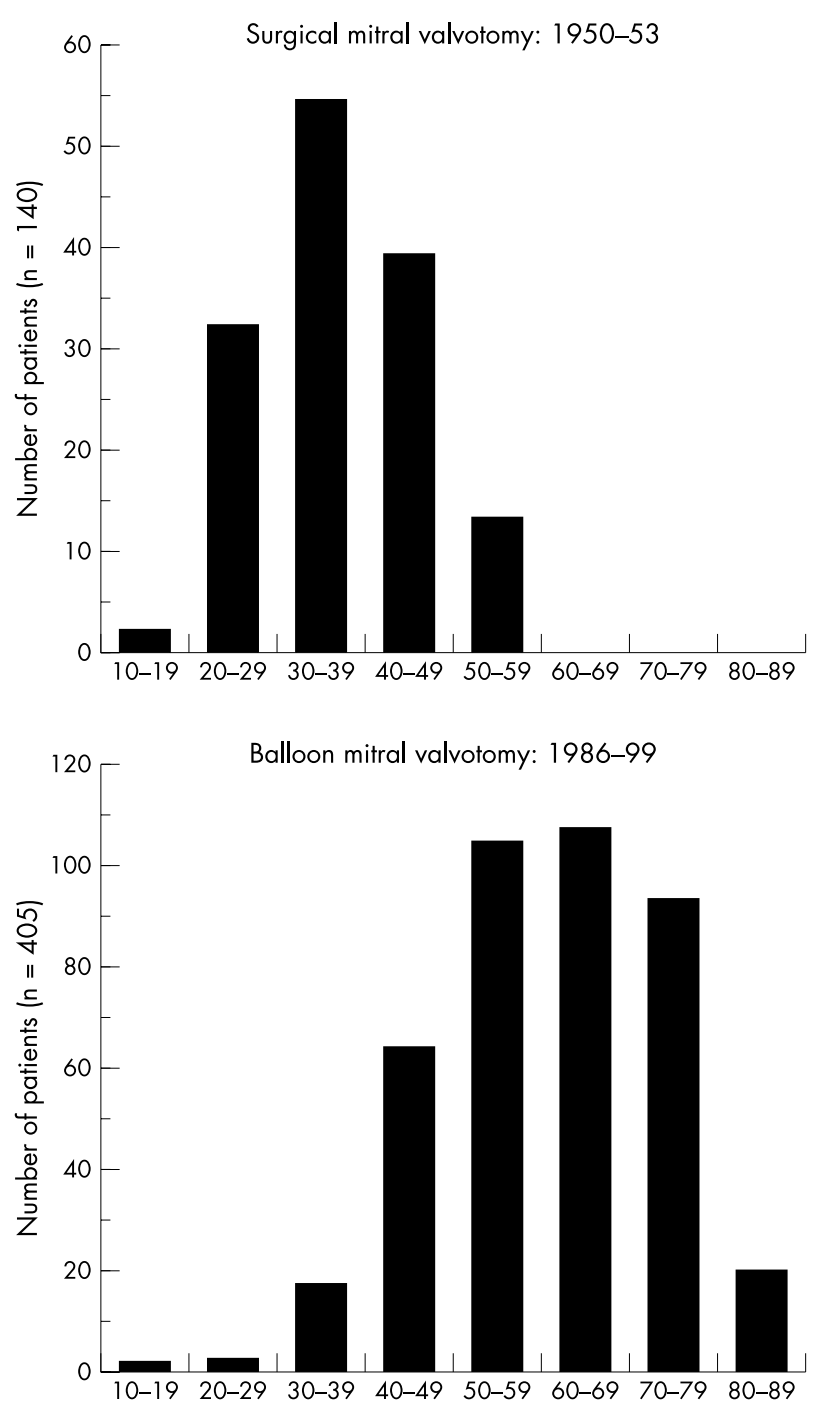

Figure 1 Age distribution of patients of the Western General Hospital who underwent surgical mitral valvotomy during 1950 to 1953 (upper panel) and percutaneous balloon valvotomy during 1986 to 2000 (lower panel). mitral reflux, left ventricular impairment, and aortic valve disease became more common with age but the trend did not reach significance.

Women formed a high proportion of the patients at all ages. A past history of rheumatic fever was present in approximately $40 \%$ for all ages except the youngest group. Only one of the youngest group had a previous mitral valvotomy. In the group aged over 70 a surgical valvotomy had been carried out in $20 \%$ at a mean of 25.3 (7.5) years earlier (range 12-40 years).

Symptomatic limitation at the time of balloon valvotomy increased significantly with age, despite more intensive diuretic treatment.

Age was correlated with mitral valve degenerative change, whether assessed by fluoroscopic calcification $(r=0.35$, $\mathrm{p}<0.001)$, echo score $(r=0.39, \mathrm{p}<0.001)$, or commissural echo calcification $(r=0.12, \mathrm{p}<0.05)$. The relation between the echo score and age is shown in fig 2 : while there was a significant correlation there was considerable individual variation and some very elderly patients still had thin pliant valves.

Owing to co-morbidity and frailty, a much higher proportion of elderly patients was judged unsuitable for surgical treatment. The Parsonnet score, which estimates the percentage risk of death at operation, increased from 10.2 to 24.6 between the youngest and oldest age groups, and the numbers of those considered unsuitable for surgical treatment increased progressively within age group, from $0 \%$ to $6 \%, 22 \%$, and $60 \%$.

\section{Haemodynamics}

The mean right ventricular systolic pressure and mean left atrial pressure recorded before balloon dilatation did not vary with age (table 2). However, the youngest patients had a much higher gradient than the older ones, despite a larger mitral orifice area, and this was associated with a higher cardiac output and a lower left ventricular end diastolic pressure. After final balloon dilatation the younger patients had a significantly lower mean left atrial pressure and lower left ventricular end diastolic pressure than the older patients, but a similar residual gradient. The increase in valve area and the final valve area were greater in younger patients.

\section{Complications}

The complications of balloon valvotomy had a tendency to increase with age (table 2). The most common complication was an increase in mitral reflux. In the four patients aged under 40 who developed increased mitral reflux this represented a change from absent to mild reflux only. In all, five patients developed severe mitral reflux requiring subsequent valve replacement, although none required emergency surgery. Thirty nine patients were found to have

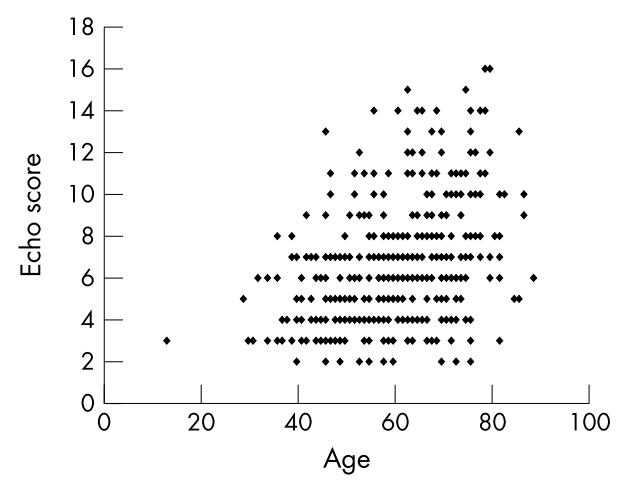

Figure 2 Relation between echo score and age $(r=0.39)$. 
Table 2 Haemodynamic findings before and after mitral balloon valvotomy

\begin{tabular}{|c|c|c|c|c|c|}
\hline & \multicolumn{4}{|c|}{ Age group (years) } & \multirow[b]{2}{*}{$\mathrm{p}$ Value } \\
\hline & $<\mathbf{4 0}$ & $40-54$ & $55-69$ & $\geqslant 70$ & \\
\hline \multicolumn{6}{|l|}{ Prevalvotomy } \\
\hline RV systolic pressure $(\mathrm{mm} \mathrm{Hg})$ & $54(21)$ & 49 (19) & $52(18)$ & $56(20)$ & 0.07 \\
\hline Mean $\mathrm{LA}$ pressure $(\mathrm{mm} \mathrm{Hg})$ & $26(8)$ & $25(7)$ & $25(7)$ & $25(7)$ & 0.97 \\
\hline Mean LVEDP (mm Hg) & $8(4)$ & $12(4)$ & $13(5)$ & $13(5)$ & $<0.001$ \\
\hline Valve gradient $(\mathrm{mm} \mathrm{Hg})$ & $18.9(8.4)$ & $13.2(4.6)$ & $12.3(5.0)$ & $11.4(4.7)$ & $<0.001$ \\
\hline Cardiac output (I/min) & $4.70(1.12)$ & $3.90(0.92)$ & $3.56(0.91)$ & $3.30(0.84)$ & $<0.001$ \\
\hline Valve area $\left(\mathrm{cm}^{2}\right)$ & $0.99(0.31)$ & $0.97(0.30)$ & $0.94(0.31)$ & $0.86(0.27)$ & $<0.05$ \\
\hline \multicolumn{6}{|l|}{ Post-valvotomy } \\
\hline Mean LA pressure $(\mathrm{mm} \mathrm{Hg})$ & $15(7)$ & $20(7)$ & $21(7)$ & $21(7)$ & $<0.01$ \\
\hline Mean LVEDP (mm Hg) & $10(5)$ & $15(5)$ & $15(6)$ & $16(6)$ & $<0.001$ \\
\hline Valve gradient $(\mathrm{mm} \mathrm{Hg})$ & $7.3(3.7)$ & $6.0(3.1)$ & $5.6(2.9)$ & $5.4(2.8)$ & 0.05 \\
\hline Cardiac output (1//min) & $5.94(2.62)$ & $4.68(1.33)$ & $4.22(1.15)$ & $4.06(1.59)$ & $<0.001$ \\
\hline Valve area $\left(\mathrm{cm}^{2}\right)$ & $2.04(0.78)$ & $1.86(0.76)$ & $1.73(0.64)$ & $1.59(0.63)$ & $<0.01$ \\
\hline $\begin{array}{l}\text { Mean increase in valve area } \\
\left(\mathrm{cm}^{2}\right)\end{array}$ & $1.05(0.69)$ & $0.89(0.62)$ & $0.79(0.54)$ & $0.74(0.50)$ & $<0.05$ \\
\hline \multicolumn{6}{|l|}{ Complication of MBV } \\
\hline Increase in mitral reflux & $4(21 \%)$ & $24(24 \%)$ & $27(16 \%)$ & $23(21 \%)$ & 0.40 \\
\hline ASD >1.2:1 & $0(0 \%)$ & $10(10 \%)$ & $14(8 \%)$ & 15 (13\%) & 0.23 \\
\hline Systemic embolism & $0(0 \%)$ & $0(0 \%)$ & $4(2.3 \%)$ & $3(2.7 \%)$ & 0.38 \\
\hline
\end{tabular}

a left to right shunt greater than $1.2: 1$ at the atrial catheter crossing point. The shunt exceeded 2:1 in only three, one of whom required later surgical repair of the atrial septum. The atrial shunt usually diminished or disappeared at follow up echocardiography. Seven of the 405 patients (1.7\%), all aged 55 or over, developed evidence of systemic embolism during or within 48 hours of the procedure: two had transient foot ischaemia, three developed evidence of coronary embolism with non-critical myocardial impairment, one had transient diplopia, and one developed a persistent hemiparesis two days after valvotomy. One other patient, aged 75 , developed severe hemiplegia before the valvotomy was completed.

Of the 416 patients who had a completed or incomplete valvotomy, one died during the procedure $(0.2 \%)-$ she developed cardiac tamponade from perforation of the left ventricular apex by a cylindrical balloon. Two other patients developed tamponade but underwent successful surgical repair. In a further two patients, a small haemopericardium was detected by post-valvotomy echocardiography. Two patients, aged 65 and 69, died before hospital discharge at two and three days after their valvotomy, one from a severe stroke which developed during the procedure, and one from complications of lupus erythematosus and cerebrovascular disease. Although many of the elderly patients were unwell, frail, and sometimes moribund, they tolerated percutaneous mitral valvotomy well. No other patients developed cardiogenic shock, acute pulmonary oedema, newly sustained atrial or ventricular arrhythmia, or required a vascular repair procedure.

\section{Outcome and predictors of outcome}

The percentages of patients in each ascending age group who achieved a valve area greater than $1.50 \mathrm{~cm}^{2}$ after final balloon dilatation without developing severe mitral reflux were $79 \%, 65 \%, 60 \%$, and $48 \%$. On multivariate analysis the independent predictors of this criterion of success were a larger initial mitral valve area (odds ratio (OR) 1.79, 95\% confidence interval (CI) 1.54 to $2.10 ; \mathrm{p}<0.001$ ); not being female (OR $0.85,95 \%$ CI 0.77 to $0.94, p<0.002$ ), less fluoroscopic mitral calcification $(p<0.05)$, less commissural echo calcification (OR $0.93,95 \%$ CI 0.88 to 0.99 ; $\mathrm{p}<0.021$ ), and absence of atrial fibrillation (OR $0.91,95 \%$ CI 0.83 to $1.00 ; \mathrm{p}<0.04)$. If haemodynamic variables were not included then the independent predictors of this outcome were a lower echo score, male sex, commissural echo calcification, and sinus rhythm.

The mean improvement in NYHA symptom class at the three to four month initial follow up was 1.22, 1.15, 1.22, and 1.18 (NS).

For determination of long term outcome, the initial 300 patients had follow up assessment for up to 10 years. Follow up in this group was $97 \%$ complete. Mean (SD) follow up was 2.4 (2.3) years. The Kaplan-Meir survival curves for each age group are shown in fig 3. Overall survival without mitral valve replacement or repeat mitral balloon valvotomy at one, three, five, and seven years was $70 \%, 60 \%, 49 \%$, and $42 \%$, respectively. Survival without mitral valve replacement or repeat mitral balloon valvotomy and with continued symptomatic improvement by $1+$ NYHA symptom class of one, three, five, and seven years was $61 \%, 52 \%, 42 \%$, and $33 \%$ (fig 4 ). On the Cox regression model for multivariate analysis of predictors of poor long term outcome using 28 variables,

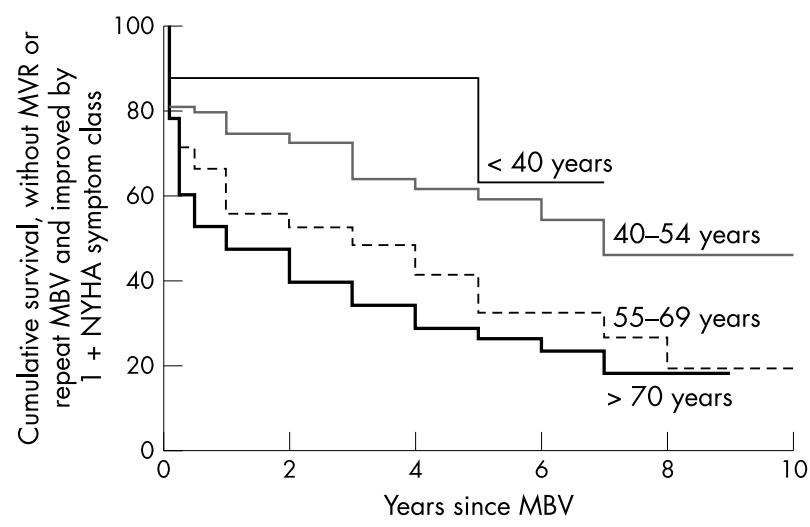

Figure 3 Cumulative survival without need for mitral valve replacement or repeat mitral balloon valvotomy and with symptomatic improvement by at least 1 NYHA symptom class in each of the four age groups. 


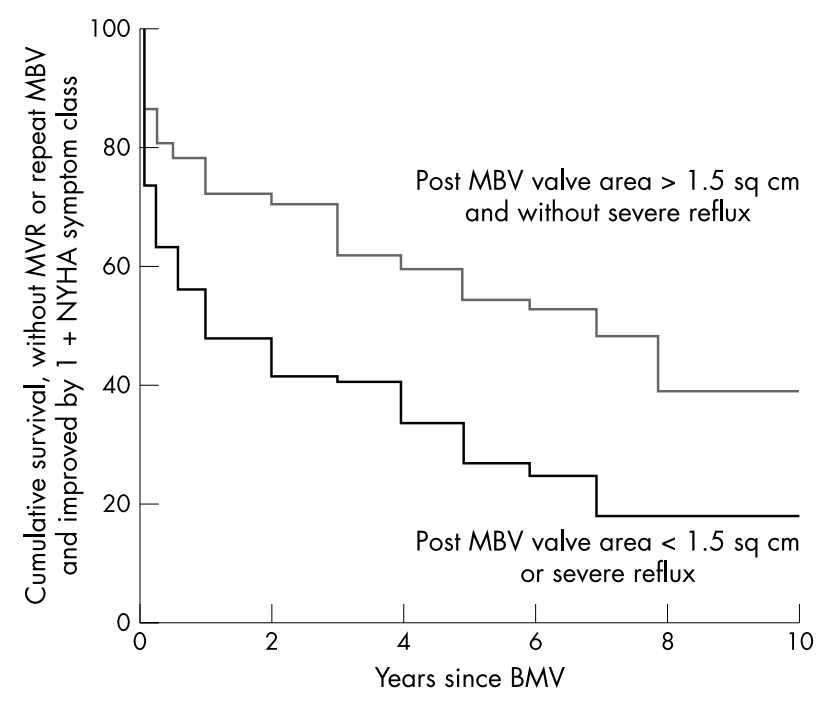

Figure 4 Cumulative survival without need for mitral valve replacement or repeat mitral balloon valvotomy (MBV) and with symptomatic improvement by at least 1 NYHA symptom class in patients who did and did not achieve a successful haemodynamic result at mitral balloon valvotomy.

nine factors were independent predictors of adverse outcome: increase in valve area (relative risk (RR) $0.29,95 \%$ CI 0.18 to $0.47 ; \mathrm{p}<0.001)$, mean left atrial pressure before dilatation (RR 0.95, 95\% CI 0.93 to $0.98 ; \mathrm{p}<0.001$ ), Parsonnet score (RR 1.04, 95\% CI 1.02 to 1.06; p $<0.001$ ), left ventricular end diastolic pressure (RR $1.07,95 \%$ CI 1.02 to $1.11 ; \mathrm{p}<0.002)$, severity of mitral reflux after final dilatation (RR $1.46,95 \%$ CI 1.14 to $1.88 ; \mathrm{p}<0.003$ ), cardiac output after final dilatation (RR $1.21,95 \%$ CI 1.05 to $1.40 ; \mathrm{p}<0.01$ ), commissure score (RR 1.29, 95\% CI 1.06 to 1.57 ; p $<0.01$ ), left ventricular impairment (RR $1.68,95 \%$ CI 1.11 to 2.54 ; $\mathrm{p}<0.01$ ), and mitral reflux before first dilatation (RR 1.42, 95\% CI 1.02 to $1.98 ; \mathrm{p}<0.05)$. The Kaplan-Meir curves for patients who did and did not achieve a successful haemodynamic result, for echo scores less than or above 8 , and for three ranges of Parsonnet score are shown in figs 5 and 6 .

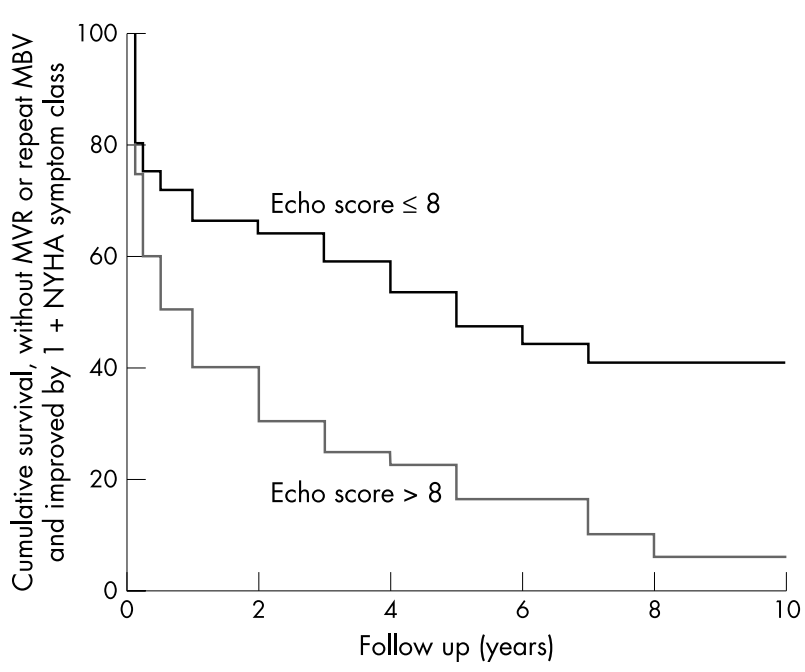

Figure 5 Cumulative survival without need for mitral valve replacement or repeat mitral balloon valvotomy and with symptomatic improvement by at least 1 NYHA symptom class in patients with an echo score of 8 or less and in those with echo score of more than 8.

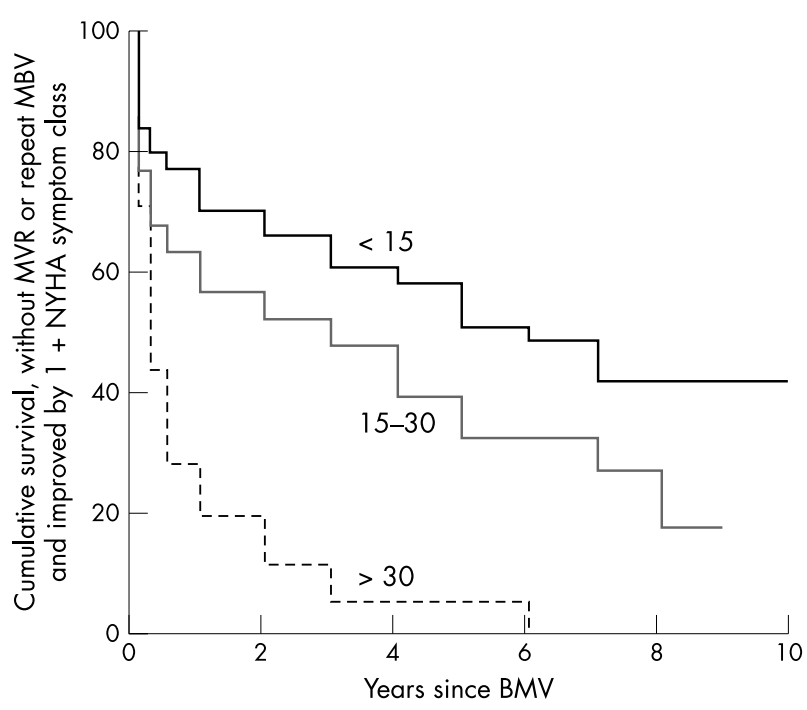

Figure 6 Cumulative survival without need for mitral valve replacement or repeat mitral balloon valvotomy and with symptomatic improvement by at least 1 NYHA symptom class in patients with Parsonnet scores of less than 15, 15-30, and more than 30 .

\section{DISCUSSION}

Our patients with severe mitral stenosis who required balloon valvotomy were now on average 24 years older than those who underwent surgical mitral valvotomy at our hospital when the operation was introduced in the 1950s. In the 1930s it was found that $61 \%$ of patients with mitral valve disease were aged under $40,{ }^{3}$ compared with $6 \%$ in our series.

The results of our review illustrate the pronounced effect of age on the clinical characteristics, haemodynamics, and outcome of treatment of patients with severe mitral stenosis who undergo percutaneous balloon valvotomy. Before mitral balloon valvotomy older patients were more symptomatically limited despite higher diuretic doses and had a more severe degree of stenosis, reflecting the more active desired lifestyle of younger patients and a tendency in older patients to avoid intervention and to maintain medical treatment until a more advanced stage. Co-morbidity, both cardiac and non-cardiac, increased substantially with age. The increased age of presentation of mitral stenosis in the UK has resulted in mitral stenosis being less frequently an isolated medical problem. This resulted in many of the older patients, particularly those over 70 , being judged as presenting too high a risk to be suitable for valve replacement. In these patients percutaneous balloon valvotomy was undertaken as a palliative procedure even if the mitral valve anatomy was unattractive for balloon commissurotomy. This selection factor would contribute to our finding that valve degenerative changes increased with age.

In patients with thin pliant valve leaflets and little subvalvar change, randomised trials have shown balloon dilatation to have an equal immediate and long term benefit to that of open and closed surgical commissurotomy ${ }^{16-21}$ and the percutaneous procedure has the advantage of greater patient comfort, short convalescence, and avoidance of postthoracotomy complications. Balloon mitral valvotomy has therefore now replaced surgical valvotomy for those patients suitable for a commissurotomy (except for cases with some forms of anticoagulant resistant left atrial thrombus) in most centres in western Europe and in many centres in developing countries. In our patients mitral balloon dilatation gave excellent haemodynamic improvement and sustained symptomatic improvement in patients aged under 40 and, to a lesser extent, in patients of 40-54 years of age. These younger 
patients had less mitral valve degenerative change, as assessed by fluoroscopic calcification, echo score, and commissural echo calcification. However, in the UK there are now relatively few such young patients with mitral stenosis. In developing countries mitral stenosis is common even in childhood. ${ }^{2}$ Of the patients in our series $29 \%$ who were aged under 40 , including the only teenage patient, had immigrated to the UK from countries where rheumatic fever remains prevalent. In the 1980s the USA had over seven million immigrants from countries where rheumatic fever was common ${ }^{9}$ and also a few localised outbreaks of acute rheumatic fever in established populations. ${ }^{22-25}$ The youngest Scottish patient was 31 years of age. In Scotland all hospital discharge diagnoses are coded and recorded on a central computer base: a case note audit is being undertaken to determine if acute rheumatic fever has now been entirely eliminated.

In the older age groups the outcome of mitral balloon valvotomy was more mixed. At five years after balloon valvotomy only $36 \%$ of patients aged 55-69 remained in NYHA symptom classes I or II, while $25 \%$ had a mitral valve replacement and $31 \%$ had died. The corresponding figures for those aged over 70 were $19 \%, 7 \%$, and $59 \%$, respectively. In some of these older patients their co-morbidities contributed to continued symptomatic limitation and mortality. However, haemodynamic outcome was less good in the older age groups, in whom valve degenerative change was more common. Of patients aged over 55, 84 of 202 (42\%) had been judged unsuitable for surgical treatment, and in these cases mitral balloon dilatation was undertaken as a palliative procedure even when valve anatomy was unattractive for a commissurotomy. For these patients a modest improvement in symptoms was beneficial when it allowed the patient to leave hospital and maintain an independent lifestyle. ${ }^{26} 27$ However, in those who were suitable for mitral valve replacement it would be helpful to be able to predict with high accuracy the ones who would obtain a good haemodynamic outcome from mitral balloon dilatation. In this respect echocardiography is still disappointing. Like others, we found the echo score to give a weak although significant correlation with increase in valve area. The variables assessed by the echo score are semiquantitative but also subjective ${ }^{28}$ and the subvalvar changes are particularly difficult to quantify. Inclusion of commissural morphology is of added benefit in case selection for those patients with an echo score of 8 or less. $^{13}$

The haemodynamic profile of our patients changed with age. The older patients had a more severe degree of mitral stenosis but younger patients had a higher transmitral gradient associated with a higher cardiac output. The mean right ventricular systolic and left atrial pressures were similar in all age groups before dilatation. Abbo and colleagues found similar haemodynamic trends in younger and older patients. ${ }^{29}$ Left ventricular end diastolic pressure was higher in the older age groups, which could be explained in part by the greater frequency of left ventricular impairment and associated coronary artery disease. Younger subjects showed a greater haemodynamic improvement after balloon dilatation, reflecting their lesser degree of valve degenerative change. Complications had a tendency to be more frequent in the older patients, although severe and persistent adverse effects were uncommon and percutaneous mitral balloon valvotomy was well tolerated even in very frail and ill older patients.

Other clinical features of mitral stenosis have changed since Wood reviewed his experience of mitral valve disease in the early 1950s. ${ }^{30}$ A history of rheumatic fever is now less common than the $68 \%$ noted by Wood. ${ }^{30}$ In his series of 300 patients, 83 had pregnancies associated with mitral stenosis, compared with only one of our 405 patients. He found an $18 \%$ incidence of severe haemoptysis, while this symptom was reported by only two of our patients $(0.5 \%)$. As most of our patients came from other cardiac centres we did not have an accurate record of incidence of systemic embolism, but it appeared much lower than the 66\% incidence in Wood's patients who had atrial fibrillation (39\% of total). At operation $23 \%$ of his patients had left atrial thrombus, which was a much higher proportion than we found at transoesophageal echocardiography (warfarin was not available at that time but was used by $92 \%$ of our patients).

This series describes the characteristics of a national series of Scottish patients who underwent mitral balloon valvotomy, but does not include all patients with severe mitral stenosis. Those with calcific valves who were suitable for operation would have been referred direct for surgery at their local hospital. Patients with severe co-morbidities were more likely to be referred for percutaneous valvotomy. Elderly patients with severe mitral stenosis who were adequately maintained on medical treatment, even with some symptomatic limitation, may not have been referred for balloon valvotomy or surgery.

\section{Conclusions}

Young patients with severe stenosis of pliant mitral valves are now uncommon in the UK, but can be effectively treated by percutaneous balloon dilatation. In older patients there is a greater tendency for valve degenerative change in addition to commissural fusion, and such patients often have comorbidities. Thus they pose a challenge for case selection, but balloon valvotomy is well tolerated even by frail or critically ill patients, and can be a useful palliative procedure for those judged unsuitable to undergo operation.

\section{Authors' affiliations}

T R D Shaw, N Sutaria, B Prendergast, Department of Cardiology, Western General Hospital, Edinburgh, UK

\section{REFERENCES}

1 Vendsburg P, Faverholdt L, Olesen $\mathrm{H}$. Decreasing incidence of a history of acute rheumatic fever in chronic rheumatic heart disease. Cardiologia 1968;53:332-40.

2 Di Sciascio G, Taranta A. Rheumatic fever in children. Am Heart J 1980;99:635-58.

3 Wood P. Rheumatic fever and active rheumatic carditis (chapter 9) and Chronic rheumatic heart disease (chapter 10). In: Diseases of the heart and circulation. London: Eyre and Spottiswoode, 1968.

4 Bach F, Hill NG, Preston TW, et al. Juvenile rheumatism in London. Ann Rheum Dis 1939;1:210-41.

5 Parkinson J. Rheumatic fever and heart disease. Lancet 1945;ii:657-63.

6 Perry CV. The aetiology of heart disease. BMJ 1934;i:278-80.

7 Parkinson J, Hartley R. Early diagnosis of rheumatic valvular disease in recruits. Br Heart J 1946;8:212-32.

8 Rowantree LG. Rheumatic heart disease and the physical fitness of the nation as seen by selective service. J Pediatr 1946;26:220-9.

9 Carroll JD, Feldman T. Percutaneous mitral balloon valvotomy and the new demographics of mitral stenosis. JAMA 1993;270:1731-6.

10 Parsonnet V, Dean D, Bernstein AD. A method of uniform stratification of risk for evaluating the results of surgery in acquired adult heart disease. Circulation 1989;79(suppl I):3-12.

11 Shaw TRD, Turnbull CM, Currie P, et al. A comparison of cylindrical and Inoue balloon techniques for mitral valvotomy in patients in the United Kingdom. $\mathrm{Br}$ Heart J 1994;72:486-91.

12 Wilkins GT, Weyman AE, Abascal VM, et al. Percutaneous balloon dilatation of the mitral valve: an analysis of echocardiographic variables related to outcome and mechanism of dilatation. Br Heart J 1988;66:299-308.

13 Shaw TRD, Sutaria N, Northridge DB. The significance of commissural calcification on outcome of percutaneous mitral balloon valvotomy. Heart 2000;84:398-402.

14 Inoue K. Percutaneous transvenous mitral commissurotomy using the Inove balloon. Eur Heart J 1991;12(suppl B):99-108.

15 Hall RJC, Julian DG. Diseases of the cardiac valves. Edinburgh: Churchill Livingstone, 1989.

16 Patel JJ, Sharma D, Mithra AS, et al. Balloon valvuloplasty versus closed commissurotomy for pliable mitral stenosis: a prospective haemodynamic study. J Am Coll Cardiol 1991;18:1318-22. 
17 Turi ZG, Reyes VP, Raju AR, et al. Percutaneous balloon versus surgical closed commissurotomy for mitral stenosis: a prospective, randomised trial. Circulation 1991;83:1179-85.

18 Shrivastava S, Mathur A, Dev V, et al. Comparison of immediate haemodynamic response of closed mitral commissurotomy, single balloon and double balloon valvuloplasty in rheumatic mitral stenosis. J Thorac Cardiovasc Surg 1992;104:1264-7.

19 Arora R, Nair M, Kalva GS, et al. Immediate and long term results of balloon and surgical closed valvotomy: a randomised comparative trial. Am Heart J 1993; 125:1091-4.

20 Reyes VP, Raju BS, Wynne J, et al. Percutaneous balloon valvuloplasty compared with open surgical commissurotomy. N Engl J Med 1994;331:961-7.

21 Farhar MB, Ayani M, Maatouk F, et al. Percutaneous balloon versus surgical closed and open commissurotomy: seven year follow up results of a randomised trial. Circulation 1998;97:245-50.

22 Veasley IG, Weidmeier SF, Orsmond GS, et al. Resurgence of acute rheumatic fever in the intermountain area of the United States. N Engl J Med 1987:316:421-7.
23 Congani B, Rizzo C Congani J et al Outbreak of acute rheumatic fever in north east Ohio. J Pediatr 1987; 111 :176-9.

24 Wald ER, Dashefsky B, Feidt C, et al. Acute rheumatic fever in Western Pennsylvania and the tristate area. Pediatrics 1987;80:371-4.

25 Papadimos T, Escamitia J, Garst $P$, et al. Acute rheumatic fever at a naval base training centre - San Diego, California. JAMA 1988;259:1782-7

26 Sutaria N, Elder AT, Shaw TRD. Long term outcome of percutaneous mitral balloon valvotomy in patients aged 70 and over. Heart 2000:83:433-8.

27 lung B, Cormier B, Farah B, et al. Percutaneous mitral comissurotomy in the elderly. Eur Ht J 1995; 16:1092-9.

28 Post JR, Feldman T, Isner J, et al. Inoue balloon mitral valvotomy in patients with severe valvular and subvalvular deformity. J Am Coll Cardiol 1995;25: 1129-36.

29 Abbo K, Carroll JD, Feldman T, et al. The impact of age on the hemodynamic features of mitral stenosis [abstract]. Clin Res 1992; 40:682A.

30 Wood P. An appreciation of mitral stenosis. BMJ 1954;i:1051-63, and ii: $1113-24$.

\section{IMAGES IN CARDIOLOGY}

\section{Anomalous origin of the pulmonary artery from the left coronary artery}

A

3 year old girl with cyanotic congenital heart disease had ventricular septal defect and pulmonary atresia.

The arterial saturation was $76 \%$. Confluent central pulmonary arteries were seen from suprasternal view on echocardiography, but the origin was not clear. A cardiac catheterisation to delineate the details of pulmonary artery anatomy showed two small major aortopulmonary collaterals supplying the left upper and right upper part of the lungs, but the central pulmonary arteries were not seen on descending thoracic aortogram. An ascending aortogram subsequently showed the pulmonary artery arising from the coronary artery. Selective injection into the left coronary artery showed dilated proximal segment of the left coronary artery and main pulmonary artery was arising from it as a first branch (right).

The pulmonary blood supply in patients with ventricular septal defect and pulmonary atresia is highly variable. Some form of coronary artery to pulmonary artery collaterals may be present in up to $10 \%$ of these patients, but the origin of pulmonary arteries from coronary arteries (through a fistulous communication, or directly) is rare. In $70 \%$ of cases, the left coronary artery is a source of pulmonary blood flow. Severe cyanosis, or increased pulmonary blood flow with congestive heart failure, pulmonary hypertension and pulmonary artery aneurysm, have been described in such patients. Coronary artery steal may be expected, but usually does not occur. Surgical correction using autologous material, or a homograft to connect the pulmonary artery to the right ventricle, and ligation or unifocalisation of collateral supply are reported.

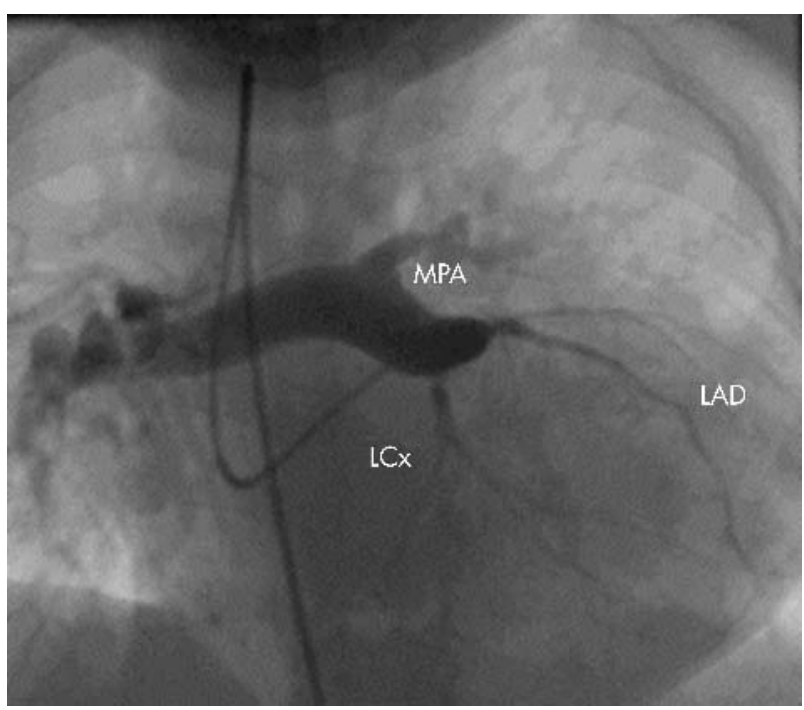

Selective injection into the left coronary artery (right anterior oblique view) showing the pulmonary artery arising from the left coronary artery. $M P A$, main pulmonary artery; $L A D$, left anterior descending coronary artery; LCX, left circumflex artery.

S S Kothari

N K Goyal

kothariss@vsnl.com 